$\underline{\text { Review Article }}$

\title{
REVIEW ON ANTIHYPERLIPEDEMIA LIPOPHILIC DRUGS AND THEIR NOVEL FORMULATION APPROACHES
}

\author{
SANTOSH SHELKE ${ }^{*}$, ASHWINI KHAIRNAR ${ }^{1}$, VIVEK RATHOD ${ }^{2}$, YOGESH KALAWANE${ }^{1}$, ASHISH JAGTAP ${ }^{1}$
}

${ }^{1}$ Department of Pharmaceutics, Yash Institute of Pharmacy, Bajaj Nagar, Aurangabad 431134, Maharashtra, India, ${ }^{2}$ University Department of Chemical Technology, Dr. Babasaheb Ambedkar Marathwada University, Aurangabad 431005, Maharashtra, India

Email: santoshshel@gmail.com

Received: 20 Apr 2017 Revised and Accepted: 13 Jul 2017

\begin{abstract}
It has been ranked as one of the greatest risk factors contributing to prevalence and severity of coronary heart diseases (CHD). CHD, stroke, atherosclerosis and hyperlipidemia are the primary cause of death. The increased levels of serum total cholesterol and low density lipoprotein (LDL) have been reported as a primary risk factor for cardiovascular disease. Hyperlipidemia is irregularly elevated levels of any or all lipids or lipoproteins in the blood i.e. fatty substances are found in the blood. Many drugs have been reported to inihibit the enzymes responsible for the synthesis of Cholesterol. Wherein, solubility is the key parameter for any active ingredient to maintain the desired therapeutic effects. Since various types of formulations are being currently prepared to enhance its solubility which in turn may improve the bioavailability of the drug? Studies reveal that different methodologies were carried out to overcome the bioavailability issue which is the key limiting factor. The present study focuses on the different types of novel formulation approaches of lipid soluble drug.
\end{abstract}

Keywords: Hyperlipidemia, Lipids, Treatment, Bioavailability, Novel formulation

(C) 2017 The Authors. Published by Innovare Academic Sciences Pvt Ltd. This is an open access article under the CC BY license (http://creativecommons.org/licenses/by/4.0/) DOI: http://dx.doi.org/10.22159/ijpps.2017v9i9.19301

\section{INTRODUCTION}

Hyperlipidemia is a condition when abnormally high levels of lipids $i$. e. the fatty substances are found in the blood. This condition is termed as hypercholesterolemia/hyper lipoproteinemia. Human body is multifarious machinery and for maintaining the homeostasis of various organ and their physiologically related systems. Any objectionable change will disturb the balance leading to a diseased state. Lipids are fats in the blood stream, commonly distributed into cholesterol and triglyceride where cholesterol is circulated in the bloodstream and is involved in the structure and function of cells [1]. Triglycerides (TG) are best viewed as energy that is either used immediately or stored in fat cells. TG are manufactured in the liver from the foods or by being absorbed from the intestine [2]. In a modification of this hypothesis, it was proposed that the endothelium normally influences the behavior of arterial smooth muscle cells by providing a barrier to the passage of plasma proteins and that the major effect of hemodynamic or other factors that injure endothelium is to reduce the effectiveness of the barrier. Arteries are normally smooth and unobstructed on the inside, but in the case of increased lipid level, a sticky substance called plaque is formed inside the walls of arteries. This leads to reduced blood flow, leading to stiffening and narrowing of the arteries. It has been proved that elevated plasma levels of cholesterol and of LDL is responsible for atherosclerosis in man, and epidemiological data suggests that elevated plasma levels of High-density lipoprotein (HDL) have a protective effect. The elevation of serum total cholesterol and (LDL) cholesterol has been reported as a primary risk factor for CVD. Many drugs used as the inhibitors of enzyme which is responsible for the synthesis of cholesterol. Solubility is one of the main parameters for any drug to achieve the expected therapeutic effects [3]. Since various types of formulations are being currently prepared to enhance its solubility which in turn may improve the bioavailability of the drug? Studies reveal that different methodologies were carried out to overcome the bioavailability issue which is the key limiting factor $[4,5]$. The present review focuses on the antihyperlipedemia lipophilic drugs and different types of novel formulation approaches of lipid soluble drug [6].

\section{Classification of lipid concentration}

The cholesterol along with some other types of fats cannot be dissolved in the blood. Moreover, in order to be transported to and from cells, they have to be specially carried by certain molecules called lipoproteins, which consist of an outer layer of protein with an inner core of cholesterol and TGs. In addition, the lipoproteins have been found essential for cholesterol to move around the body [7]. The lipids can be classified as

\section{Total cholesterol}

According to guidelines of National Cholesterol Education Program (NCEP), TC concentrations below $200 \mathrm{mg} / \mathrm{dl}$ have been regarded as desirable, whereas, concentrations greater than $240 \mathrm{mg} / \mathrm{dl}$ are referred to as hyperlipidemic. However, epidemiological evidence suggests that the risk of cardiac events decreases as TC levels fall approximately to $150 \mathrm{mg} / \mathrm{dl}$. Moreover, TC should be less than $180 \mathrm{mg} / \mathrm{dl}$ for children [8].

\section{Triglyceride}

TGs are another type of fat that is carried in the blood by VLDL. The excess calories, alcohol or sugar in the body get converted into TGs and stored in fat cells throughout the body. The TG concentration less than $150 \mathrm{mg} / \mathrm{dl}$ is regarded as normal, whereas, concentrations of $200-499 \mathrm{mg} / \mathrm{dl}$ are considered as high. Moreover, concentrations of $500 \mathrm{mg} / \mathrm{dl}$ or higher are considered lethal for the development and progression of various CVDs [9].

\section{LDL cholesterol}

LDL is commonly known as the bad cholesterol, which is produced by the liver and carry cholesterol and other lipids from the liver to various areas of the body muscles, tissues, organs and heart [10]. The high levels of LDL indicate excess cholesterol in the blood stream than necessary leading to the risk of heart disease. According to NCEP guidelines, less than $100 \mathrm{mg} / \mathrm{dl}$ concentrations of LDL cholesterol are considered optimal, whereas concentrations in the range of $160-189 \mathrm{mg} / \mathrm{dl}$ are considered to the higher side. However, increasing evidence supports that normal human LDL cholesterol concentration can be as low as 50 to $70 \mathrm{mg} / \mathrm{dl}$. Moreover, it has been comprehensively seen that the risk of CVDs decreases as LDL cholesterol concentration decreases [11].

\section{HDL cholesterol}

HDL is commonly referred to as the good cholesterol, which is produced by the liver to carry cholesterol and other lipids from 
tissues back to the liver for degradation. High levels of HDL cholesterol have been considered as a good indicator of a healthy heart. The concentrations of $60 \mathrm{mg} / \mathrm{dl}$ or higher have been considered as optimal, whereas, HDL concentrations below 40 $\mathrm{mg} / \mathrm{dl}$ are considered as major risk factor for CVDs [12]. However, HDL is often interpreted in the context of TC and LDL concentrations, and hence may be regarded as less significant when LDL is low.

\section{VLDL cholesterol}

VLDL cholesterol is the lipoproteins that carry cholesterol from the liver to organs and tissues in the body. They are formed by a combination of cholesterol and TGs. Moreover, VLDLs are heavier than LDL, and are also associated with atherosclerosis and heart disease [13].

\section{Chylomicorns}

Chylomicrons are the lipoprotein particles that transport dietary lipids from the intestines to other parts of the body. It is manifested by the absorptive cells of the small intestine. Chylomicrons are constitutes of $85 \%$ - 92\% TGs, $6 \%$ - 12\% phospholipids, $1 \%-3 \%$ cholesterol, and $1 \%-2 \%$ protein. These particles deal with the transport of dietary lipids to the liver, adipose, cardiac, and skeletomuscular tissues. The majority of chylomicrons are deactivated in the blood by the enzyme lipoprotein lipase within 12 to 14 hours [14]

\section{Enzymes involved in lipoprotein metabolism}

Lipoprotein lipase (LPL), Hepatic lipase (HL), Lecithin cholesterol acyl transferase (LCAT), Cholesteryl ester transfer protein (CETP), Microsomal TG protein (MTP), Acyl Co-A transferase (ACAT) [15]

\section{Mechanism of lipid transport}

Lipids are insoluble in water. Hence, they are transported around the body as lipoproteins. Lipids originate from two sources: endogenous lipids, synthesized in the liver, and exogenous lipids, ingested and processed in the intestine. Approximately $7 \%$ of body's cholesterol circulates in plasma in the form of (LDL). The level of plasma cholesterol is influenced by its synthesis and catabolism in which liver plays a crucial role (fig. 1).

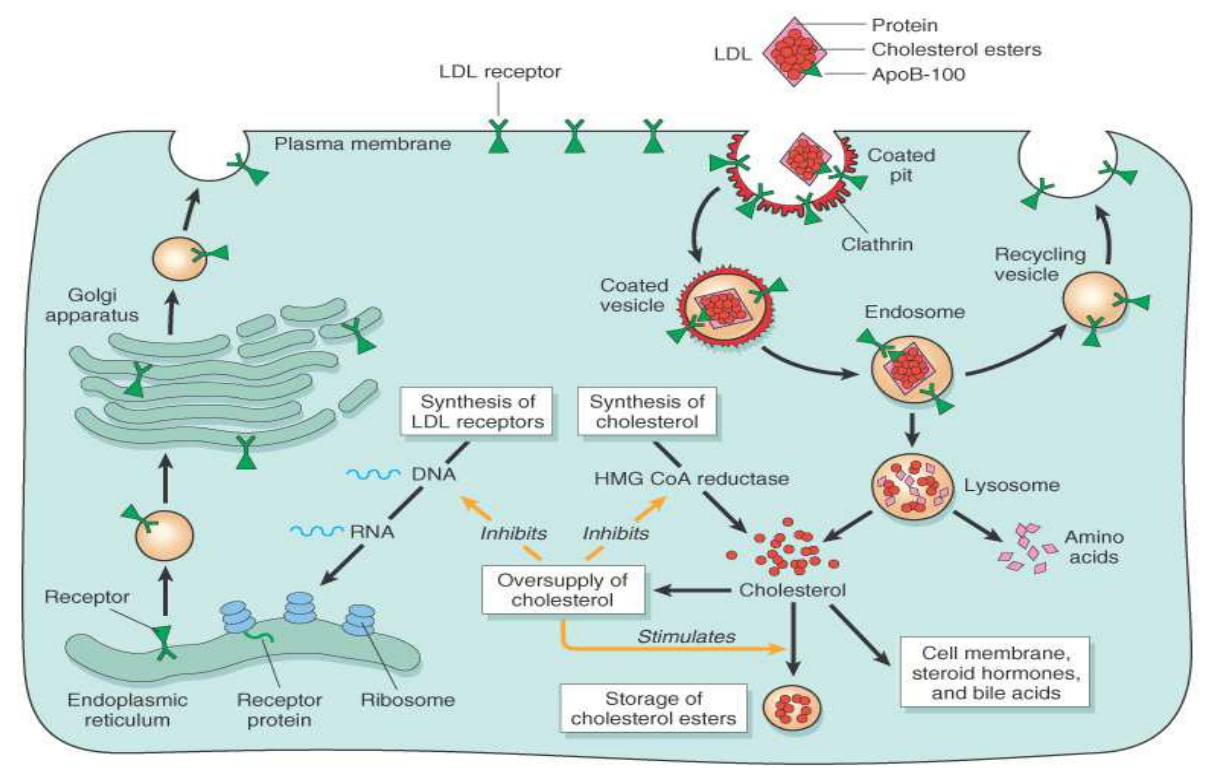

Fig. 1: Mechanism of lipid transport [2]

\section{Types of hyperlipidemia}

Hyperlipidemia can be broadly divided into

\section{A) Primary hyperlipidemia}

\section{Single gene defect}

It is familial and called as monogenic or Genetic

\section{Polygenic gene defect}

Multiple genetic defects, dietary and physical activity are caused which are expressed in table 1.

\section{B) Secondary hyperlipidemia}

It is associated with diabetes, myxoedema, nephritic syndrome, chronic alcoholism, with the use of drugs like corticosteroids, oral contraceptives, Beta blockers (table 2).

Table 1: Types of primary hyperlipidemia $[15,[16]$

\begin{tabular}{lllll}
\hline Type & Disorder & Cause & Occurance & Elevated plasma lipoprotein \\
\hline I. & Familial lipoprotein lipase deficiency & Genetic & Very rare & Chylomicorns \\
IIa. & Familial hypercholesterolemia & Genetic & Less common & LDL \\
IIb. & Polygenic hypercholesterolemia & Multifactorial & Commonest & LDL \\
III. & Familial dysbetalipoproteinemia & Genetic & Rare & IDL, Chylomicrons Remnants \\
IV. & Hypertriglyceridemia & Multifactorial & Common & VLDL \\
& & Genetic & & \\
V. & Familial combined Hyperlipidemia & Genetic & Less common & VLDL, LDL \\
\hline
\end{tabular}

LDL-low density lipoprotein, VLDL-very low-density lipoprotein, IDL-intermediate density lipoprotein. 
Table 2: Types of secondary hyperlipidemia $[17,18]$

\begin{tabular}{ll}
\hline Type & Reasons \\
\hline Hypercholesterolemia & $\begin{array}{l}\text { Hypothyroidism, Anorexia nervosa, Acute intermittent porphyria, Obstructive liver disease, Nephrotic syndrome, Drugs: } \\
\text { Progestins, thiazide diuretics, glucocorticoids, beta blockers, isotretinoin, protease inhibitors, cyclosporine, mirtazapine, } \\
\text { sirolimus. }\end{array}$ \\
Hypertriglyceridemia & $\begin{array}{l}\text { Obesity, Pregnancy, Lipodystrophy, Acute hepatitis, Diabetes Mellitus, Ileal bypass surgery, Glycogen storage disease, } \\
\text { Systemic lupus erythematosus, Monoclonal gammopathy: multiple myeloma, Drugs: Alcohol, estrogens, isotretinoin, beta } \\
\text { blockers, glucocorticoids, bile-acid resins, thiazides, asparaginase, interferons, azole antifungals, mirtazapine, anabolic } \\
\text { steroids, sirolimus, bexarotene. } \\
\text { Hypercholesterolemia } \\
\text { Lalnutrition, Malabsorption, Chronic liver disease, Myeloproliferative diseases, Chronic infectious diseases: AIDS, } \\
\text { tuberculosis } \\
\text { Malnutrition, Obesity, Drugs: anabolic steroids, probucol, isotretinoin, progestins. }\end{array}$ \\
\hline
\end{tabular}

\section{- Signs and symptoms of hyperlipidemia}

Hyperlipidemia usually has no noticeable symptoms and tends to be discovered during routine examination or evaluation for atherosclerotic CVD [19]. Commonly found are Xanthoma, Xanthelasma of the eyelid, Chest Pain, Abdominal Pain, Enlarged Spleen, Liver Enlarged, High cholesterol or TG levels, Heart attacks, a Higher rate of obesity and glucose intolerance, Pimple like lesions across the body, Atheromatous plaques in the arteries, Arcussenilis, Xanthomata [20].

\section{- Causes of hyperlipidemia}

Lifestyle habits or treatable medical conditions. Lifestyle contributors include obesity, not exercising, and smoking, Diabetes (type 2), Kidney disease, Pregnancy, An under active thyroid gland, Environmental and genetic factors, Alcohol, Monoclonal Gammopathy, Nephrotic Syndrome, Obstructive Jaundice, Hypothyroidism, Cushing's Syndrome, Anorexia Nervosa, High dietary simple carbohydrates, Estrogen therapy [21].

\section{Treatment therapy}

\section{Non-pharmacological therapy}

The objectives of dietary therapy are to decrease the intake of total fat, saturated fatty acids (i. e., saturated fat), and cholesterol progressively and to achieve a desirable body weight.

- $\quad$ Reduced saturated and total fat intake to 7 percent and 25 to 35 percent of daily calories respectively.

- Optimized dietary cholesterol to less than $200 \mathrm{mg}$ per day.

- Eating 20 to $30 \mathrm{~g}$ a day of soluble fibre, which is found in oats, peas, beans, and certain fruits [22].

- Increased intake of plant sterols or sterols, substances found in nuts, vegetable oils, corn and rice, to 2 to $3 \mathrm{~g}$ daily.

Other foods that can help control cholesterol include cold-water fish, including mackerel, sardines, and salmon. These fish oils contain omega-3 fatty acids that may lower TGs [23]. Soybeans found in tofu and soy nuts and many meat substitutes contain a powerful antioxidant that can lower LDL [24].

Laparoscopic sleeve gastrectomy (LSG) leads to long-term weight loss and improvement or resolution of its associated comorbidities such as diabetes Mellitus (DM), hypertension, and hyperlipidemia [25].

\section{Pharmacological therapy}

\section{Classification of drugs}

a. HMG-CoA reductase inhibitors (Statins): Lovastatin, Simvastatin, Pravastatin, Atorvastin, Rosuvastin

b. Bile acid sequestrants (Resins): Cholestyramine, Colestipol

c. Activate lipoprotein lipase (Fibric acid derivatives): Clofibrate, Gemfibrozil, Benzafibrate and Fenofibrate.

d. Inhibit lipolysis and TG synthesis: Nicotinic acid.

e. Others: Ezetimibe, Gugulipid

\section{Conventional drug delivery system used for hyperlipidemia}

Non-invasive peroral route of administration, where the dosage form is consumed through the mouth, is the most conventional way for delivering the anti hyperlipidemic drugs [26]. This route has certain limitations such as drugs with short half-life requires frequent administration, which increases chances of missing dose of drug leading to poor patient compliance. It is difficult to obtain a steady state condition due to unavoidable fluctuations in the drug concentration. First pass metabolic effect on the drugs is another major limitation of this route which reduces the bioavailability of several important drugs [27] Moreover, variability is also seen due to the presence of food, physiological parameters of the body, diseased condition etc. In a nutshell, the shortcomings of conventional dosage forms can be summarized a sun favorable bio distribution, low bioavailability, lack of water solubility, poor site specificity, low therapeutic response despite high doses and elevated side effects and toxicity. To overcome these limitations, development of novel drug delivery systems (NDDS) which include drug modification (chemically or physically) [28], drug entrapment within lipidi corpolymeric small vesicles or particle size reduction of drugs, is necessary [28]. This advent of NDDS will not only reduce the shortcomings of drugs which are cited pharmacologically and biopharmaceutically but will also aid to remove the drawbacks of conventional drug delivery system [29].

\section{Novel formulation approaches}

Sustained/controlled release of following drugs is achieved through the novel methods of formulating a drug incorporated carrier system. Table 3 outlines various novel formulation approaches of drug carried out in different studies.

Table 3: Clinically approved statins - comparative properties [30]

\begin{tabular}{lllllll}
\hline $\begin{array}{l}\text { S. } \\
\text { No. }\end{array}$ & Name of the drug & $\begin{array}{l}\text { Bio- } \\
\text { availability(\%) }\end{array}$ & $\begin{array}{l}\text { Protein binding } \\
\text { (\%) }\end{array}$ & $\begin{array}{l}\text { Elimination Half- } \\
\text { life(h) }\end{array}$ & Solubility & $\begin{array}{l}\text { Source } \\
\text { reduction (\%) }\end{array}$ \\
\hline 1 & Atorvastatin & 12 & 98 & 14 & Lipophilic & synthetic \\
2 & Cerivastatin & 60 & $>99$ & 2.5 & Lipophilic & synthetic \\
3 & Fluvastatin & 24 & $>98$ & 1.2 & Lipophilic & synthetic \\
4 & Lovastatin & 5 & $>95$ & 3 & Lipophilic & fungal derived \\
5 & Pravastatin & 18 & $\sim 50$ & 1.8 & hydrophilic & fungal derived \\
6 & Simavastatin & 5 & $95-98$ & 24 & Lipophilic & fungal derived \\
7 & Rosuvastatin & 20 & 90 & 19 & hydrophilic & synthetic \\
8 & Pitavastatin & $\sim 80$ & 96 & 11 & lipophilic & synthetic \\
\hline
\end{tabular}


Various novel drug delivery systems which can help to overcome the limitations of various drugs and the conventional dosage forms pertaining to them. As a result, different novel drug delivery systems have been developed which are discussed in the subsequent sections. Novel Formulation Approaches for Lipophilic Drugs

\section{Self-emulsifying drug delivery system}

Self-emulsifying drug delivery systems (SEDDS) are the class of emulsions formulated to enhance the oral bioavailability of the poorly absorbed drugs, which can be made available as either self micro emulsifying drug delivery system (SMEDDS) or self-nano emulsifying drug delivery system (SNEDDS), which can be differentiated based on their droplet size. Basicaly SNEDDS are the mixtures of an oil, surfactant, co-surfactant and active pharmaceutical agent. The basic principle of this system is its ability to form oil-inwater $(\mathrm{o} / \mathrm{w})$ micro emulsions under gentle agitation following dilution by aqueous phases. The digestive motility of the stomach and intestine provide this agitation which is required for the spontaneous formation of an emulsion in vivo in the lumen of the gut. This process presents the drug in a solubilized form and the small size of the formed droplet provides a large interfacial surface area for drug absorption. Furthermore, lipids present in the formulation helps to improve he bioavailability interfering the drug absorption. Researches have been reported on the formulation of SEDDS of Lovastatin with an objective to increase the solubility which ultimately helps to lower the levels of bad cholesterol to attain the desired therapeutic action. [31,32].

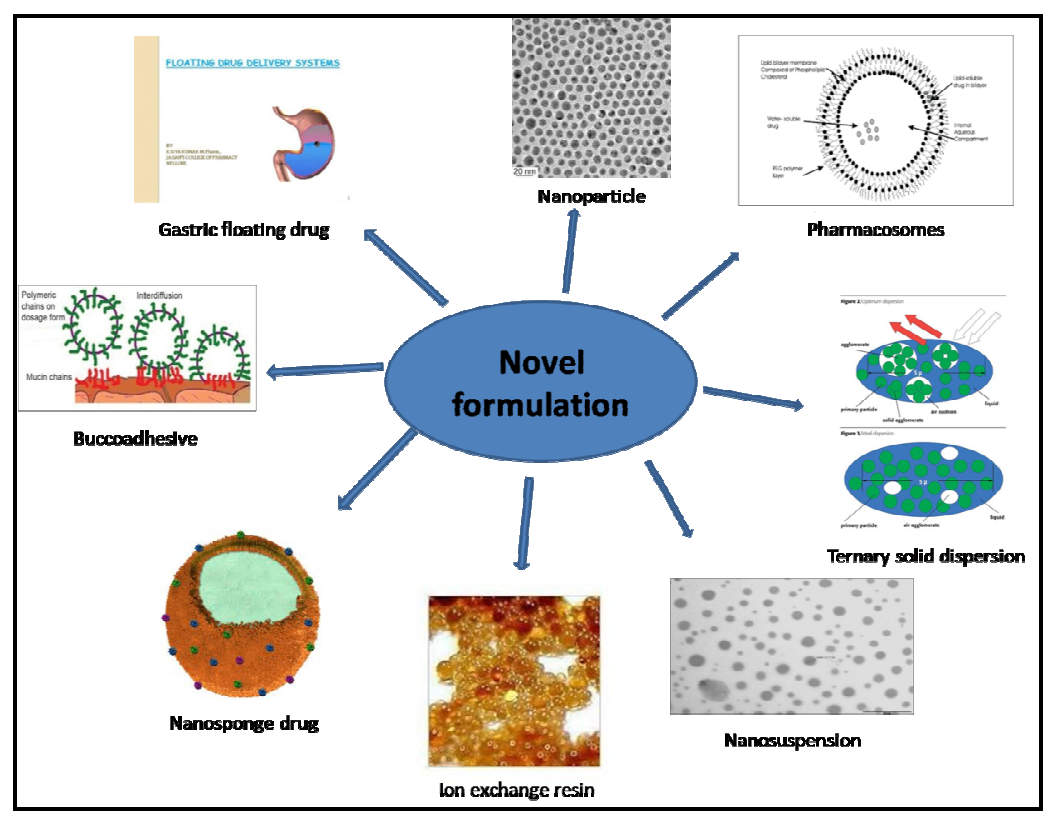

Fig. 2: Novel formulation approaches for lipophilic drugs

\section{Ternary solid dispersions}

Solid dispersions is the method of choice widely selected for solubility enhancement and improving the bioavailability of poorly water soluble drugs. There are different types of solid dispersion systems characterized according to the physical states of the drug and the carrier in the systems [33]. It may be a molecular solid solution, a dispersion of amorphous or crystalline drug particles in an amorphous carrier matrix or a combination of a solution and dispersion of solids. Due to its higher lipophilicity (fig. 2) drugs tend to practically insoluble in water. As Fenofibrate is lipophilic in nature absorption is the limiting factor in gastrointestinal tract Solubility enhancement of fenofibrate was seen on the formulation of solid dispersion using poloxamer 188 and TPGS (Tocopheryl Polyethylene Glycol Succinate). The investigation was carried to prepare solid dispersions of fenofibrate using polyethylene glycols of different molecular weights along with anionic and non-ionic surfactants by melt method and it was observed that solubility of the drug was enhanced from $4.14 \mu \mathrm{g} / \mathrm{ml}$ to $63.67 \mu \mathrm{g} / \mathrm{ml}$, which was an increase of $15 \mathrm{folds}$. Solid dispersion along with an adsorption technique that employs a water-soluble adsorbent like Gelucire was used to enhance the dissolution of Ezetimibe, which may have resulted from the combined effect of hydrophilic carriers and increased surface area [34, 35].

\section{Nanosuspension}

Nanosuspension is a submicron colloidal dispersion of drug particles that are produced by suitable methods and stabilized by surfactants. This range of particle range leads to a significant increase in the dissolution rate and bioavailability. Nanosuspensions are framed to increases the surface area and saturation solubility (fig. 2). TRICOR is a marketed nanosuspension which consists of Fenofibrate which has proven to be a better product in the market as compared to the other marketed products of the same drug. The prepared formulation has reported to increase the therapeutic efficacy of the drug and was found to reduce the possible side effects. Researchers have investigated nano suspensions using several lipophilic antihyperlipidemic drugs like ezetimibe and simvastatin and have obtained satisfactory results to increase the solubility and thereby dissolution of these highly lipophilic drugs [36-37].

\section{Ion exchange resins}

Ion exchange resins are crosslinked, water insoluble, carrying ionisable acidic or basic functional groups having the ability to interchange the counterions with the aqueous solutions surrounding them. Drugs can be loaded onto the resins by an exchanging reaction forming a drug-resin complex (fig. 2). The drug is released from these complexes by exchanging with ions in the gastrointestinal fluid, followed by drug diffusion. Ion-exchange systems are advantageous for drugs that are highly susceptible to degradation by an enzymatic process. Cholestyramine resin USP, when used as an active ingredient, binds bile acids and lead to their replenishment through increased metabolism of serum cholesterol resulting in lowered serum cholesterol levels. This proved to be very effective in enhancing the bioavailability of the drugs due to the utilization of some polymers, which enhances the cost of the delivery system $[38,39]$.

\section{Nanosponge drug delivery}

Nanosponges contain polymers like $\beta$ - cyclodextrin and its derivatives which contain both lipophilic and hydrophilic groups. These polymers are arranged in such a way that they form cavities 
which are capable of carrying a variety of drugs (fig. 2). Use of these unique polymers helps in improving the solubility of poorly water soluble molecules, reducing side effects by controlling the release, improving stability, increasing elegance and enhancing formulation flexibility. Atorvastatin, Fenofibrate, Lovastatin were formulated into nanosponges. Atrovastatin was found to be compatible with $\beta$ cyclodextrin and was completely encapsulated in nanosponges. The optimized formulation showed good dissolution release profile of more than $75 \%$ atorvastatin within 60 mins in $0.1 \mathrm{~N}$ HCL which indicated that the solubility of atorvastatin was improved by forming nanosponges [40].

\section{Buccoadhesive drug delivery system}

The buccal membrane is a highly vascular membrane and consists of buccal mucosa which is a smooth and immobile surface that facilitates the placement of buccoadhesive dosage forms.

Buccoadhesive Drug deliverys systems are formulated for the drugs those are susceptible to first pass metabolism, GI degradation, with aqueous solubility. (fig. 2). Buccoadhesion is achieved by using various types of hydrophilic polymers. Several studies on anti-hyperlipidemic drugs, particularly statins have been performed. Buccoadhesive tablets of Lovastatin was developed which increased the bioavailability of the drug. Buccoadhesive fast dissolving films containing Pravastatin sodium were prepared using polyvinyl alcohol and naturally occurring ocimum bacilicum mucilage powder where it demonstrated faster drug release with less disintegration time. Buccoadhesive tablets of Simvastatin were prepared by direct compression, using Carbopol940 and naturally occurring Sodium Alginate. Investigations have helped to build the contact with buccal mucosa, avoid the first pass metabolism increased absorption and patient compliance, which ultimately resulted in an enhanced drug bioavailability [41].

\section{Gastric floating drug delivery system (microsphere)}

Gastric Floating drug delivery systems are dynamically controlled systems. Gastric floating drug delivery systems are meant for delivery the drug in desired order where the drug release can be controlled. Various approaches to retain the drug in the stomach are low-density systems, Buoyancy tablets, floating microspheres, and mucoadhesive tablets. (fig 2). It also improves bioavailability, reduces drug dumping and dosing frequency and improves solubility for drugs that are less soluble in high $\mathrm{pH}$ environment [42]. These characteristics were seen in a delivery system formulated in the form of microcapsules of cholestyramine coated with cellulose acetate butyrate. These microcapsules had the ability to produce carbon dioxide when exposed to a gastric fluid which allows them to float. They were distributed throughout the stomach and exhibited prolonged gastric residence via mucoadhesion. Gastric floating drug delivery system of fenofibrate was prepared which demonstrated increased absorption and bioavailability with $90 \%$ of drug release in $10 \mathrm{~h}$ where floating lag time was reported to be of $50 \mathrm{sec}$ and floating time of $24 \mathrm{~h}$. a similar formulation was also developed using simvastatin which showed a considerable increase in the gastric retention [43].

\section{Pulsatile drug delivery system}

Pulsatile Drug Delivery System is useful in the diseases in which the drug release is timed to match rhythms of the disease so as to optimize the therapeutic effect and minimize the side effects. Circadian rhythm occurs during hepatic cholesterol synthesis which is higher during the night than daylight. Hence it has been the challenge for the researchers to formulate the dosage form which confirms the therapeutic effects at right time by delivering the drug in optimum amount for the patients with the high lipid contents to coincide with the circadian rhythm of the body. This approach is also referred to as the chrono therapeutic drug delivery system. Statins are usually taken in one daily dose in the evening, presumably to coincide with cholesterol synthesis, which is thought to peak in the early morning hours. A pulsatile drug delivery of simvastatin was formulated which was taken before bed time $(9 \mathrm{pm})$ and released drug after a predetermined time delay which was 5hours, thereby being therapeutically more active and efficient in the early morning hours when free cholesterol levels are more prevalent. Sharma et al. (2016) developed the pulsatile release tablets of Pravastatin sodium which showed an increased lag time with an increase in the concentration of coated polymers whereby, obtaining the objective of chronotherapeutic Hyperlipidemia. Recent studies have suggested that the expression of PPAR $\alpha$-dependent fibroblast growth factor 21 (FGF21) plays important roles in lipolysis and ketogenesis and it was found that a night time injection of bezafibrate (lignadofPPAR $\alpha$ ) effectively induced FGF21 expression, whereas a daytime injection did not affect it. These observations suggest that bezafibrateinduced circadian FGF21 expression is due to circadian variations in the responsiveness of the PPAR $\alpha$ system in the liver [44, 45]

\section{Nanoparticle formulation}

Nanomaterials have unique physicochemical properties, such as ultra-small size, large surface area to mass ratio and high reactivity, which allows the modification of the fundamental properties such as solubility, diffusivity, blood circulation half-life, drug release characteristics, and immunogenicity (fig. 2). Nanocrystalline fenofibrate under the brand name TRICOR are drug nanoparticles with the crystalline character which are a clinically approved nanoparticle formulation. This formulation has not only increased the therapeutic efficacy of the drug but also helped in minimizing the toxic adverse effects. Nanocrystalline at orvastatin was also prepared which improved the solubility to 60 -folds when compared to pure drug. Lipid nanoparticles have been the best carrier system for the colloidal carriers, such as polymeric nanoparticles, liposomes, conventional oilin-water emulsions, and nanoemulsions. The biocompatibility of lipids and their capability to enhance oral bioavailability of drugs have made nanoparticles an interesting carrier for oral delivery. Lipidic nanoparticles of Simvastatin were prepared and it was observed that drug was released in a sustained manner from the lipid carrier system. Absorption of simvastatin was 8.99 times higher than a plain drug which shows enhancement of bioavailability at the same dose. A novel approach of conjugates of polymeric nanoparticle was also developed, where the researchers used biodegradable and biocompatible epolylactide nanoparticles (100 nm in diameter) with covalently attached apo lipoprotein B100 antibody to adsorb LDLs at physiologically relevant concentrations. About six fold decreases in LDL levels was found using LDL suspensions $(500 \mathrm{mg} / \mathrm{dl})$ with anti-apoB100-nanoparticle conjugates. An in-vivo study was performed which exhibited that macrophages can quickly take up antibody-nanoparticle-LDL complexes and digest them within $24 \mathrm{~h}$, without any evidence of cytotoxicity. Another novel drug delivery system is nano emulsion which consists of emulsified oil and water having an average droplet size between 100 and $500 \mathrm{~nm}$. The capacity of nanoemulsion to dissolve large quantities of poorly soluble drugs to protect them from hydrolysis and enzymatic degradation make it an ideal drug delivery vector. Nanoemulsion of Simvastatin was prepared where the optimized formulation demonstrated higher release of about (99.28\%), when compared with conventional suspension [46, 47].

\section{Prodrug formulations}

Prodrugs are chemically modified versions of a pharmacologically active agent, which must undergo a transformation in vivo to release the active drug. The use of a prodrug strategy as a chemical/biochemical approach is to overcome various hurdles which can hinder drug delivery and solubility in GI tract. The major applications of the prodrug strategy is to improve oral absorption and aqueous solubility, increase lipophilicity, enhance active transport, as well as achieve site-selective delivery. MB07811 is an internally discovered HepDirect prodrug of a novel liver targeted thyroid hormone receptor (TR- $\beta$ ) agonist for treating hyperlipidemia, whose action is limited to the liver, which reduces its exposure to other tissues and thereby affects the levels of cholesterol, TGs and other lipoproteins that are associated with increased cardiovascular risk. Thyroid hormone receptor agonists are known to reduce lipids in animal models, but typically at doses similar to those associated with potential safety concerns, including cardiac and other on-hepatic toxicities. Liver-targeting may avoid the safety concerns previously seen with on-liver targeted TR $\beta$ agonists and thus unlock the therapeutic potential of this approach. MB07811 is an unapproved prodrug. If approval is given to it then it could be one of the first in an entirely new class of antihyperlipidemic agents which may help 
patient's better reach targeted lipid levels either as first line therapy or in combination with statins [48].

\section{Pharmacosomes}

These are the amphiphilic lipid vesicular systems containing phospholipid complexes with the characteristic potential to improve solubility, absorptivity and bioavailability of both poorly water soluble as well as poorly lipophilic drugs (fig. 2). They are colloidal dispersions of drugs covalently bound to lipids. Depending upon the chemical structure of the drug-lipid complex they may exist as ultrafine vesicular, micellar, or hexagonal aggregates. As the system is formed by linking a drug (pharmakon) to a carrier (soma), they are termed as "Pharmacosomes" [49]. They are an effective tool to achieve desired therapeutic goals such as drug targeting and controlled release.

\section{Recent formulation techniques}

Dissolution process is the rate-controlling step for hydrophobic drugs which shows erratic and incomplete absorption from the GI tract. Thus, one of the major challenges to drug development today is poor solubility, as estimated $40 \%$ of all newly developed drugs are poorly soluble or insoluble in water. In addition, up to $50 \%$ of orally administered drug compounds suffer from formulation problems related to their lipophilicity. As a result, enormous research has been conducted in the methods of improving drug solubility and dissolution rates to increase the oral bioavailability of the hydrophobic drugs.

Other formulation principles are also available which employs some of the novel methods for improving the solubility and bioavailability of the lipophilic drugs [50].

\section{$>$ Pearl milling}

An aqueous suspension of the drug is filled in a pearl mill containing glass/zirconium oxide pearls as milling media. The nanoparticles are formed due to movement of milling pearls. The effect is depending on drug properties, medium and stabilizer.

Eg. Rapamune, an immunosuppressant agent is developed using nanocrystal technology and approved by FDA [51].

\section{$>$ High-pressure homogenization}

An aqueous surfactant solution containing the drug (dispersed) is passed through a high-pressure homogenizer. The nanoparticles are formed due to cavitations force. This process depends on the hardness of drug, the processing pressure and the number of cycles applied. This technique offers several advantages like increased saturation solubility, dissolution rate, amorphous fractions, bioavailability, and surface modification of the particles and possibility of large scale production [52].

\section{$>$ Solution enhanced dispersion (SEDs)}

This is achieved by the Supercritical fluid process (SCF). The organic solution of the drug is mixed with the compressed fluid CO2in the mixing chamber with help of a coaxial nozzle which flows into a vessel through a restricted orifice where the particles are formed.
The solution is disintegrating into droplets due to high frictional surface forces.

\section{$>$ RESAS processes (Rapid Expansion from Supercritical to Aqueous Solution)}

This process induces nucleation of the SCF dissolved drugs and surfactants with a desirable particle size in a very short time. Surfactants can stabilize the particle and suppress particle agglomeration.

\section{$>$ Spray freezing into liquid (SFL)}

The solution/emulsion/suspension containing the drug in aqueous/ organic/combination of both phase is atomized into a compressed gas or cryogenic liquids. Then the particles are frozen and lyophilized to obtain free flowing micronized powder.

\section{$>$ Evaporative precipitation into aqueous solution (EPAS)}

The low boiling point organic solvent containing lipophilic drug is pumped after the temperature is raised above the boiling point of the solvent. It is sprayed through a fine atomizing nozzle into a heated aqueous solution. The presence of surfactants in both phases will stabilize the particle formation.

\section{$>$ Complexation}

To increase the water solubility, dissolution rate and bioavailability of certain lipophilic drugs cyclodextrins are used as complexing agents. The driving forces for efficient complexation are attributed to the exclusion of high energy water from the cavity, the release of ring strain, Vander Waals interaction and hydrogen/hydrophobic bindings

\section{$>$ Solid dispersions/solutions}

One or more active ingredients are dispersed in a carrier matrix in the solid state by various techniques such as solvent evaporation, fusion or melting solvent method. Physical, chemical instability and scale up process are some of the problems arising in this technique.

\section{$>$ Water soluble carriers}

The excipients like PEGs are used to solubilize the drug by improving the wettability.

\section{$>$ Hot Homogenization with ultrasonication}

The result found from the solid lipid nanoparticle of Clozapine indicates that this method is suitable for the improvement of bioavailability of lipophilic drugs.

\section{$>$ Surfactants containing micro particles}

In the microparticle, the hydrophilic surfactant will improve the particle.

Various researches are being carried out in improving the limiting factor of solubility by means of modifying the already existing formulation into a novel form which improves the bioavailability (fig. 2). The current trend in the enhancement of efficiency of simvastatin therapy through novel formulation approaches is shown in table 4 .

\section{Table 4: Novel formulation approaches and its application}

\begin{tabular}{|c|c|c|c|}
\hline S. No. & Formulation & Materials used & Purpose \\
\hline 1. & Hydrogel & _ Gelatin & Bone regeneration \\
\hline & & _Hyaluronic acid & Osteogenesis \\
\hline & & Gelatin polyethene glycol triamine & Controlled release \\
\hline 2. & Emulsion & _Carpyral, Cremophor EL, Carbitol & Improve bioavailability \\
\hline 3. & Micelle & $\begin{array}{l}\text { _Poly(ethyleneglycol) } \\
\text { _poly(caprolactone) }\end{array}$ & Regeneration of bones \\
\hline 4. & Nanoparticles & _Tocotrienol & Combination therapy \\
\hline 5. & Implants & $\begin{array}{l}\text { - Titanium discs } \\
\text { _ Polylactic acid }\end{array}$ & Formation of bone \\
\hline 6. & Topical formulation & $\begin{array}{l}\text { _ Polyethylene glycol } \\
\text { _Pluronic, cetyl tri methyl ammium Bromide }\end{array}$ & $\begin{array}{l}\text { Sustained release } \\
\text { Immediate release }\end{array}$ \\
\hline 7. & Microspheres & Ethylcellulose & Bone tissue engineering \\
\hline 8. & $\begin{array}{l}\text { Sustained release } \\
\text { Pellets }\end{array}$ & $\begin{array}{l}\text { _ Nicotinic acid } \\
\text { Ethyl cellulose }\end{array}$ & Combination therapy and immediate release \\
\hline 9. & Tablet & Starch, Lactose & Prevention of cardiovascular events \\
\hline 10. & Liposome & __Egg phosphatidyl choline, Cholesterol & Suppression of neointimal formation \\
\hline
\end{tabular}




\section{Herbal medicines}

Currently used hypolipidemic drugs are associated with so many adverse effects and withdrawal is associated with rebound phenomenon which is not seen with herbal preparations. Plant parts or plant extract are sometimes even more potent than known hypolipidemic drugs. This indicates that the research has stopped with just reporting the effect of plant derivates and the findings are not translated into clinical research. Taking these finding forward is mandatory to develop new drugs in this area.

Hence further research into identifying the active principle, conducting preclinical studies and if possible clinical studies is needed. Here are some plants which showed antilipidemic activity [table 5].

Table 5: Important plants comprising hypolipidaemic and antihyperlipidemic activity [53-58]

\begin{tabular}{|c|c|c|c|c|}
\hline S. No. & Name of plant & Family & Common/ Indian vernacular names & Plant parts \\
\hline 1 & Aeglemarmelos & Rutaceae & Beal fruit, bilwa & Fruits \\
\hline 2 & Agave Veracruz & Rutaceae & American aloe, barakhawar & Roots, leaves, gum \\
\hline 3 & Allium cepa & Lilliaceae & Onion, piyaj, palandu & Bulbs \\
\hline 4 & Aloe barbadensis & Lilliaceae & Onion, piyaj, palandu & Leaves \\
\hline 5 & Bambusaarundunacea & Graminae & Bamboo vamsha & Leaves \\
\hline 6 & Bosswelliaserrata & Burserraceae & Salaiguggal & Gum \\
\hline 7 & Brassica vercapitata & Cruciferae & Cabbage & Oil \\
\hline 8 & Cajanuscajan & Fabaceae & Red gram & Seeds \\
\hline 9 & Capparis decidua & Capparaceae & Karli, tint & Leaves, fruits and stems \\
\hline 10 & Capsicum frutescens & Solanaceae & Chillies & Fruits \\
\hline 11 & Carumcapaticum & Umbelliferae & Jowan, ajowan & Fruits, roots \\
\hline 12 & Celastruspaniculatus & Celastraceae & Khunjri, kusur & Seed oil, barks, roots and fruits \\
\hline 13 & Curcuma amada & Zingiberaceae & Mango ginger, haridra & Rhizomes \\
\hline 14 & Cyamopsistetragonoloba & Leguminosae & Guar, gwar & Seeds \\
\hline 15 & Emblicaofficinalis & Euphorbiaceae & Amla, amlki & Dried fruits, Seeds, leaves \\
\hline 16 & Eugenia cumini & Myrtaceae & Jamun & Seeds \\
\hline 17 & Inularacemosa & Compositae & Puskarmul & Roots \\
\hline 18 & Juglansregia & Juglandaceae & Walnut, akhrot & Kernel, oil \\
\hline 19 & Medicagosativum & Papilionaceae & Alfalfa & Seeds \\
\hline 20 & Momordicacharantia & Cucurbitaceae & Alfalfa & Fruits \\
\hline 21 & Musa saspientum & Musaceae & Banana, kela & Roots, Stems, Flowers, Fruits \\
\hline 22 & Nepetahindostana & Labiatae & Billiola, badranjboya & Whole plant \\
\hline 23 & Phaseolusaureus & Fabaceae & Green gram & Seeds \\
\hline 24 & Phaseolusmungo & Fabaceae & Black gram & Seeds \\
\hline 25 & Picrohizakurroa & Scrophulariaceae & Kulki, kataki & Roots \\
\hline 26 & Piper nigrum & Piperaceae & Golmirch, kalimich & Leaves \\
\hline 27 & Pisumsativum & Papilionaceae & Garden pea, matar & Seeds \\
\hline 28 & Pterocarpusmarsupium & Papilionaceae & Indianmalabarkino & Gum and leaves \\
\hline 29 & Saussuraealappa & Asteraceae & Kustha, Kut & Roots \\
\hline 30 & Terminaliaarjuna & Combretaceae & Arjun & Barks \\
\hline 31 & Ricinuscommunis & Euphorbiaceae & Castor oil & Seeds \\
\hline 32 & Luffaacutangula & Cucurbitaceae & & Fruit \\
\hline
\end{tabular}

\section{CONCLUSION}

It has been the challenging issue for the researchers and the manufacturing units to elaborate the progress in this area. Oral route is claimed to be the most preferred route of drug administration due to its palatability. Bioavailability problems is the leading factor for therapeutic failure of certain drugs. From the economic point of view, when the drug is highly expensive a large portion of an oral dose is wasted due to poor bioavailability and leads to increased cost for drug therapy. Hence, our review was focused towards the development of some stable formulation of anti-hyperlipidemia lipophilic drugs and different types of novel formulation approaches of lipid soluble drug. The review has elaborated the theoretical concept of hyperlipidemia, different approaches involved for drug delivery of lipophilic drugs and recent formulation techniques for the development of the stable formulation which is meant to improve the absorption and bioavailability. Also, the review has commented on the herbal medicines and their uses. Hence it can be concluded that by using various techniques one can improve the oral absorption, bioavailability and therapeutic efficacy of the poorly water soluble drugs.

\section{CONFLICT OF INTERESTS}

\section{Declared none}

\section{REFERENCES}

1. Hasunuma Y, Matsuura E, Makita Z, Katahira T, Nishi S, Koike T. Involvement of b2-glycoprotein $\mathrm{I}$ and anti-cardiolipin antibodies in oxidatively modified low-density lipoprotein uptake by macrophages. Clin Exp Immunol 1997;107:569-73.

2. Dhaliya SA, Surya AS, Dawn VT, Betty C, Arun K, Sunil C. A review of hyperlipidemia and medicinal plants. IJAPS BMS 2013;2:219-37.

3. Lipinski CA, Lombardo F, Dominy BW, Feeney PJ. Experimental and computational approaches to estimate solubility and permeability in drug discovery and development settings. Adv Drug Delivery Rev 1997;23:3-25.

4. Shelke S, Shahi S, Jadhav K, Dhamecha D, Tiwari R, Patil H. Thermoreversible nano-ethosomal gel for the intranasal delivery of Eletriptan hydrobromide. J Mater Sci Mater Med 2016;27:1-3.

5. Shelke S, Shahi S, Jalalpure S, Dhamecha D. Poloxamer 407based intranasal thermoreversible gel of zolmitriptanloaded nano liposomes: formulation, optimization, evaluation and permeation studies. J Liposome Res 2016;26:313-23.

6. Gursoy RN, Benita S. Self-emulsifying drug delivery systems (SEDDS) for improved oral delivery of lipophilic drugs. Biomed Pharmacother 2004;58:173-82.

7. Nelson RH. Hyperlipidemia as a risk factor for cardiovascular disease. Prim Care 2013;40:195-211.

8. Rohilla A, Dagar N, Rohilla S, Dahiya A, Kushnoor A. Hyperlipidemia-a deadly pathological condition. Int J Curr Pharm Res 2012;4:15-8.

9. Castelli WP. The triglyceride issue: a view from Framingham. Am Heart J 1986;112:432-7. 
10. Rohilla AN, Dagar N, Rohilla S, Dahiya A, Kushnoor A Hyperlipidemia-a deadly pathological condition. Int J Curr Pharm Res 2012;4:15-8.

11. Nakamura K, Miyoshi T, Yunoki K, Ito $H$. Postprandial hyperlipidemia as a potential residual risk factor. J Cardiol 2016;67:335-9.

12. Goldstein JL, Schrott HG, Hazzard WR, Bierman EL, Motulsky AG. Hyperlipidemia in coronary heart disease II. Genetic analysis of lipid levels in 176 families and delineation of a new inherited disorder, combined hyperlipidemia. J Clin Invest 1973;52:1544.

13. Griffin BA, Freeman DJ, Tait GW, Thomson J, Caslake MJ, Packard CJ, et al. Role of plasma triglyceride in the regulation of plasma (LDL) subfractions: relative contribution of small, dense LDL to coronary heart disease risk. Atherosclerosis 1994;106:241-53.

14. Havel RJ. Approach to the patient with hyperlipidemia. Med Clin North Am 1982;66:319-33.

15. Shattat GF. A review article on hyperlipidemia: types, treatments and new drug targets. Biomed Pharm J 2015;7:399-409.

16. Havel RJ, Rapaport E. Management of primary hyperlipidemia. N Engl J Med 1995;332:1491-8.

17. Gong J, Fang K, Dong H, Wang D, Hu M, Lu F. Effect of fenugreek on hyperglycaemia and hyperlipidemia in diabetes and prediabetes: a meta-analysis. J Ethnopharmacol 2016;194:260-8.

18. Zhong J, Gong W, Lu L, Chen J, Lu Z, Li H, et al. Irbesartan ameliorates hyperlipidemia and liver steatosis in type 2 diabetic $\mathrm{db} / \mathrm{db}$ mice via stimulating PPAR- $\gamma$, AMPK/Akt/mTOR signalling and autophagy. Int Immunopharmacol 2017;42:176-84.

19. Aarthy S, HARI BV, Devi DR. Current trends in simvastatin therapy for enhanced efficiency. Int J Pharma Bio Sci 2014;5:279-88.

20. Kyriakidis AV, Raitsiou B, Sakagianni A, Harisopoulou V, Pyrgioti M, Panagopoulou A, et al. Management of acute severe hyperlipidemic pancreatitis. Digestion 2006;73:259-64.

21. Fodor JG, Frohlich JJ, Genest JJ, McPherson PR. Recommendations for the management and treatment of dyslipidemia report of the working group on hypercholesterolemia and other dyslipidemias. Can Med Assoc J 2000;162:1441-7.

22. Ullrich IH. Evaluation of a high-fiber diet in hyperlipidemia: a review. J Am Coll Nutr 1987;6:19-25.

23. Eslick GD, Howe PR, Smith C, Priest R, Bensoussan A. Benefits of fish oil supplementation in hyperlipidemia: a systematic review and meta-analysis. Int I Cardiol 2009;136:4-16.

24. Onwe PE, Folawiyo MA, Anyigor-Ogah CS, Umahi G, Okorocha AE, Afoke AO. Hyperlipidemia: etiology and possible control. IOSR J Dental Med Sci 2015;14:93-100.

25. AlKhalifa K, Al Ansari A, Alsayed AR, Violato C. The impact of sleeve gastrectomy on hyperlipidemia: a systematic review. Int J Obes 2013;1-7. http://dx.doi.org/10.1155/2013/643530

26. Mathur M, Kusum Devi V. Potential of novel drug delivery strategies for the treatment of hyperlipidemia. J Drug Target 2016:1-1. http://dx.doi.org/10.3109/1061186X.2016.1172586

27. Shelke S, Shahi S, Jalalpure S, Dhamecha D, Shengule S. Formulation and evaluation of thermoreversible mucoadhesive in-situ gel for intranasal delivery of naratriptan hydrochloride. J Drug Delivery Sci Technol 2015;29:238-44.

28. Sinkula AA, Yalkowsky SH. The rationale for the design of biologically reversible drug derivatives: prodrugs. J Pharm Sci 1975;64:181-210

29. Banerjee PS, Robinson JR. Novel drug delivery systems. Clin Pharmacokinet 1991;20:1-4.

30. Punitha S, Kumar KS. Statin therapy and their formulation approaches: a review. Int J Pharm Sci 2011;3:23-6.

31. Aarthy S, Hari BV, Devi DR. Current trends in simvastatin therapy for enhanced efficiency. Int J Pharma Bio Sci 2014;5:279-88.

32. Charman SA, Charman WN, Rogge MC, Wilson TD, Dutko FJ, Pouton CW. Self-emulsifying drug delivery systems: formulation and biopharmaceutic evaluation of an investigational lipophilic compound. Pharm Res 1992;9:87-93.

33. Kaur J, Aggarwal G, Singh G, Rana AC. Improvement of drug solubility using solid dispersion. Int J Pharm Pharm Sci 2012; 4:47-53.

34. Vasconcelos T, Sarmento B, Costa P. Solid dispersions as a strategy to improve oral bioavailability of poor water soluble drugs. Drug Discovery Today 2007;12:1068-75.

35. Gursoy RN, Benita S. Self-emulsifying drug delivery systems (SEDDS) for improved oral delivery of lipophilic drugs. Biomed Pharmacother 2004;58:173-82.

36. Hanafy A, Spahn-Langguth H, Vergnault G, Grenier P, Grozdanis MT, Lenhardt $\mathrm{T}$, et al. Pharmacokinetic evaluation of oral fenofibrate nanosuspensions and SLN in comparison to conventional suspensions of micronized drug. Adv Drug Delivery Rev 2007;59:419-26.

37. Lakshmi P, Kumar GA. Nanosuspension technology: a review Int J Pharm Pharm Sci 2010 2:35-40.

38. Glueck CJ, Ford S, Scheel D, Steiner P. Colestipol and cholestyramine resin: comparative effects in familial type II hyperlipoproteinemia. JAMA 1972;222:676-81.

39. Anand V, Kandarapu R, Garg S. Ion-exchange resins: carrying drug delivery forward. Drug Discovery Today 2001;6:905-14.

40. Mathur M, Kusum Devi V. Potential of novel drug delivery strategies for the treatment of hyperlipidemia. J Drug Target 2016;24:916-26.

41. Yedurkar P, Dhiman MK, Petkar K, Sawant K. Biopolymeric mucoadhesive bilayer patch of pravastatin sodium for Buccal delivery and treatment of patients with atherosclerosis. Drug Dev Ind Pharm 2013;39:670-80.

42. Dhiman S, Singh TG, Rehni AK, Sood S, Arora S. Gastroretentive: a controlled release drug delivery system. Asian J Pharm Clin Res 2011;4:5-13.

43. Kumar K, Shah MH, Ketkar A, Mahadik KR, Paradkar A. Effect of drug solubility and different excipients on floating behaviour and release from glyceryl monooleate matrices. Int J Pharm 2004;272:151-60.

44. Benita S. editor. Microencapsulation: methods and industrial applications. CRC Press; 2005.

45. Sharma S, Pawar A. Low-density multi particulate system for pulsatile release of meloxicam. Int J Pharm 2006;313:150-8.

46. Mishra RK, Banthia AK, Majeed AB. Pectin based formulations for biomedical applications: a review. Asian J Pharm Clin Res. 2012;5:1-7.

47. Shelke S, Shahi S, Kale S, Patil V, Deshpande D. Ethosomes: a novel deformable carrier. World J Pharm Sci 2015;9;1830-9.

48. Stella VJ, Nti-Addae KW. Prodrug strategies to overcome poor water solubility. Adv Drug Delivery Rev 2007;59:677-94.

49. Kumar PT, Mishra J, Podder A. Design, fabrication and evaluation of rosuvastatin Pharmac some-a novel sustained release drug delivery syste. Eur J Pharm Med Res 2016;3:332-50.

50. Das S, Chaudhury A. Recent advances in lipid nanoparticle formulations with the solid matrix for oral drug delivery. AAPS PharmSciTech 2011;12:62-76.

51. Punitha S, KUMAR KS. Statin therapy and their formulation approaches a review. Int J Pharm Pharm Sci 2011;3:41-4.

52. Singh BB, Vinjamury SP, Der-Martirosian C, Kubik E. Ayurvedic and collateral herbal treatments for hyperlipidemia: a systematic review of randomized controlled trials and quasi-experimental designs. Alternative Ther Health Med 2007;13:22.

53. Kaushik V, Saini V. Hyperlipidemia: its management and induction. Int J Pharm Sci Res 2014;5:3152.

\section{How to cite this article}

- Ashwini Khairnar, Santosh Shelke, Vivek Rathod, Yogesh Kalawane, Ashish Jagtap. Review on antihyperlipidemic lipophilic drugs and their novel formulation approaches. Int J Pharm Pharm Sci 2017;9(9):1-8. 